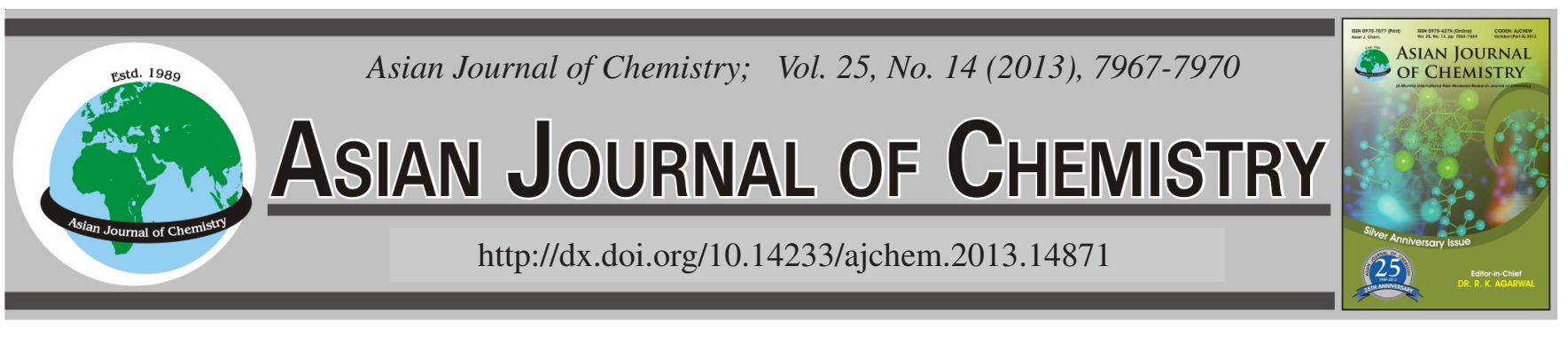

\title{
Attapulgite Based Composite Adsorbents for Adsorption Refrigeration
}

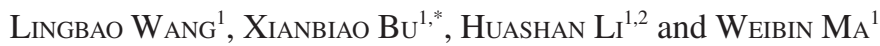

${ }^{1}$ Key Laboratory of Renewable Energy and Gas Hydrate, Guangzhou Institute of Energy Conversion, Chinese Academy of Sciences, Guangzhou 510640, P.R. China

${ }^{2}$ Graduate University of Chinese Academy of Sciences, Beijing 100864, P.R. China

*Corresponding author: Fax: +86 20 87057791; Tel: +86 20 87057792; E-mal: wanglb@ms.giec.ac.cn; buxb@ms.giec.ac.cn

\begin{abstract}
To develop a high performance adsorbent for adsorption refrigeration, the composite adsorbents of $\mathrm{CaCl}_{2} /$ attapulgite (AT) are prepared. Experimental researches are carried out to investigate the influence of the content of $\mathrm{CaCl}_{2}$ and calcination conditions such as the temperature and duration on the performance of $\mathrm{CaCl}_{2} /$ attapulgite. The results indicate that the water vapour uptake of $\mathrm{CaCl}_{2} /$ attapulgite augments with $\mathrm{CaCl}_{2}$ content increasing and the calcination conditions also have an important influence on the adsorption performance of $\mathrm{CaCl}_{2} /$ attapulgite. The optimal calcination temperature and duration are $300^{\circ} \mathrm{C}$ and $2 \mathrm{~h}$, respectively.
\end{abstract}

Key Words: Adsorption refrigeration, Composite adsorbents, Attapulgite, Calcium chloride, Immersion method.

\section{INTRODUCTION}

Adsorption refrigeration has received great attention for its effectiveness in cold production based on the low-grade waste heat or renewable energy ${ }^{1}$. Adsorption refrigeration is characterized by using environmentally friendly refrigerants, the absence of vibration, less sensitive to shocks and the low operation and maintenance costs ${ }^{2,3}$. Although the adsorption refrigerator has these advantages, at present, it cannot compete against the traditional vapour compression system due to the poor properties of the adsorption working pairs.

Two ways can be used to solve the problem. The first is stemmed from the thermodynamic views to enhance the heat and mass transfer in adsorbers, as well as use the heat and mass recovery device ${ }^{4-6}$ and the other method is the application of high adsorption quantity and low temperature regenerated adsorbents $^{7-9}$. Of them, the latter is favorable. Aristov ${ }^{10}$ indicated that the future progress of adsorption refrigeration will be possible only if innovative adsorbents with advanced properties are used.

Adsorbents used in the adsorption refrigeration can be classified into three groups, viz., physical, chemical and composite types. The physical adsorbents, e.g., silica gel, the most famous materials of this class, have small cycle adsorption quantities, big isosteric heat, slow adsorption rate and poor thermal conductivity ${ }^{11}$. Many researchers report that the chemical adsorbents have better adsorption performance than those of the physical counterparts in adsorption quantity and rate. Nevertheless, the adsorbate and adsorbent molecules never keep their original state after adsorption. Moreover, there are the phenomena of salt swelling and agglomeration, which is critical to heat and mass transfer performance. On the other hand, the composite adsorbent is promising for adsorption refrigeration, especially at reduced regeneration temperature. The superiority of composite sorbents is associated with the purposeful modification of their sorption properties ${ }^{12}$.

Several types of porous media are used to make composite adsorbents with chlorides, such as expanded graphite, activated carbon, activated carbon fiber, vermiculite, MCM-41, etc. For example, Aristov et al ${ }^{13}$ investigated silica gel/calcium chloride composite adsorbents called selective water sorbents prepared by impregnating $\mathrm{CaCl}_{2}$ into the pores cavities of silica gel. Wang et al. ${ }^{14}$ studied the consolidated composite adsorbent of $\mathrm{CaCl}_{2}$ and expanded graphite. Dellero et al. ${ }^{15}$ studied three mixtures of carbon fibers with $\mathrm{MnCl}_{2}$. Tokarev et al. ${ }^{16}$ confined $\mathrm{CaCl}_{2}$ to mesoporous host matrix MCM-41 to improve the mass transfer that caused by agglomeration.

As a type of clay, Attapulgite (AT) has an ideal water loading due to its highly porous structures and large specific surface area up to $100-300 \mathrm{~m}^{2} / \mathrm{g}$. Besides, it is very cheap and has satisfactory viscosity. If some hygroscopic material is added into attapulgite, the capacity of water loading will be enhanced. The main objective of the present study is to prepare and investigate the attapulgite-based $\mathrm{CaCl}_{2}$ composites, i.e., $\mathrm{CaCl}_{2}$ /attapulgite, for using in adsorption refrigeration. The influences of the content of $\mathrm{CaCl}_{2}$ and calcination conditions 
such as the temperature and duration on the performance of $\mathrm{CaCl}_{2}$ /attapulgite are studied.

Sample preparation: The main raw materials used in the study are shown in Table-1. The specific parameters of the oxide content of attapulgite are shown in Table- 2 .

\begin{tabular}{cccc}
\multicolumn{5}{c}{ TABLE-1 } \\
\multicolumn{5}{c}{ SPECIFICATION AND ACCURACY OF ALL } \\
MATERIALS AND MEASUREMENT DEVICES
\end{tabular}

The impregnation of the calcium chloride into the pore volumes of attapulgite comprises mainly the preparation of the aqueous calcium chloride and the immersion of attapulgite in that solution.

Dry attapulgite under the temperature of $120^{\circ} \mathrm{C}$. During the drying process, the composite adsorbents are taken out and weighed from time to time until their weight losses are found negligibly small.

Prepare a certain mass concentration (e.g. $50 \% \mathrm{wt})$ aqueous solution of calcium chloride. Put dry attapulgite into the solution and mix uniformly. Process the mixture of $\mathrm{CaCl}_{2}$ and attapulgite into spherical particles of $0.5-1.0 \mathrm{~mm}$ in diameter and then calcine the spherical particles in a muffle furnace.

In the present study, 27 samples of composite adsorbents with different calcium chloride contents, different calcination temperatures, different calcination time are prepared and the detail information is shown in Table-3.

\section{EXPERIMENTAL}

The adsorption performance including adsorption quantity and adsorption rate is measured in a temperature and humidity chamber (THC). The adsorption is generally slower than desorption in adsorption refrigeration, so the study focusing on the adsorption process is more meaningful ${ }^{17}$. The adsorption temperature and relative humidity are $40^{\circ} \mathrm{C}$ and $20 \%$, respectively. The cooling water temperature of the adsorption refrigeration driven by the waste heat is generally at $30^{\circ} \mathrm{C}$ and taking the temperature difference between the adsorption bed and the adsorbents into account, the adsorption temperature of $40^{\circ} \mathrm{C}$ is appropriate.

Firstly, put $\mathrm{CaCl}_{2} /$ attapulgite in a drying cabinet under the temperature of $90{ }^{\circ} \mathrm{C}$. During the drying process, the composite adsorbents are taken out and weighed from time to time until their weight losses are found negligibly small. Then put
TABLE-3

INFORMATION OF THE 27 SAMPLES OF COMPOSITES

\begin{tabular}{ccccc}
\hline Sample & $\begin{array}{c}\text { Conc. of } \\
\text { aqueous } \mathrm{CaCl}_{2} \\
\text { solution }(\%)\end{array}$ & $\begin{array}{c}\mathrm{CaCl}_{2} \\
\text { content } \\
(\%)\end{array}$ & $\begin{array}{c}\text { Calcination } \\
\text { temp. }\left({ }^{\circ} \mathrm{C}\right)\end{array}$ & $\begin{array}{c}\text { Calcination } \\
\text { duration } \\
(\mathrm{h})\end{array}$ \\
\hline 1 & 30 & 15 & 250 & 1 \\
2 & 30 & 15 & 250 & 2 \\
3 & 30 & 15 & 250 & 3 \\
4 & 30 & 15 & 300 & 1 \\
5 & 30 & 15 & 300 & 2 \\
6 & 30 & 15 & 300 & 3 \\
7 & 30 & 15 & 350 & 1 \\
8 & 30 & 15 & 350 & 2 \\
9 & 30 & 15 & 350 & 3 \\
10 & 40 & 20 & 250 & 1 \\
11 & 40 & 20 & 250 & 2 \\
12 & 40 & 20 & 250 & 3 \\
13 & 40 & 20 & 300 & 1 \\
14 & 40 & 20 & 300 & 2 \\
15 & 40 & 20 & 300 & 3 \\
16 & 40 & 20 & 350 & 1 \\
17 & 40 & 20 & 350 & 2 \\
18 & 40 & 20 & 350 & 3 \\
19 & 50 & 25 & 250 & 1 \\
20 & 50 & 25 & 250 & 2 \\
21 & 50 & 25 & 250 & 3 \\
22 & 50 & 25 & 300 & 1 \\
23 & 50 & 25 & 300 & 2 \\
24 & 50 & 25 & 300 & 3 \\
25 & 50 & 25 & 350 & 1 \\
26 & 50 & 25 & 350 & 2 \\
27 & 50 & 25 & 350 & 3 \\
\hline
\end{tabular}

the dried $\mathrm{CaCl}_{2} /$ attapulgite on the electronic balance placed in temperature and humidity chamber and the lasting time is $2 \mathrm{~h}$. The weight change is tested by the electronic balance and collected by the computer. The measuring range and the precision of the electronic balance equipped with computer interface are 210 and $0.001 \mathrm{~g}$, respectively. In the experiment, the data collection interval is $20 \mathrm{~s}$. It usually takes $2-5 \mathrm{~h}$ to reach the adsorption equilibrium, but for refrigeration the adsorption time of $2 \mathrm{~h}$ is sufficient.

\section{RESULTS AND DISCUSSION}

Influence of calcination duration: The preparation technology includes the $\mathrm{CaCl}_{2}$ content, calcination duration and calcination temperature. To investigate the effect of the calcination duration on the adsorption performance at the calcination temperature of $300^{\circ} \mathrm{C}$, three different samples with $\mathrm{CaCl}_{2}$ contents of 15, 20 and $25 \%$ are examined. Fig. 1 shows the variation of the water vapour uptake of three different samples with different calcination durations at the adsorption time of $2 \mathrm{~h}$ and relative humidity of $20 \%$. It can be seen from Fig. 1 that the water vapour uptake increases with the increase of $\mathrm{CaCl}_{2}$ content in samples. The water vapour uptake of $\mathrm{CaCl}_{2} /$ attapulgite with $25 \% \mathrm{CaCl}_{2}$ is $14.28 \mathrm{~g} / 100 \mathrm{~g}$, which is 1.006 and 1.138 times of the samples with $\mathrm{CaCl}_{2}$ content of 20 and $15 \%$, respectively, under the same conditions.

TABLE-2

SPECIFIC PARAMETERS OF THE OXIDE CONTENT OF THE ATTAPULGITE

\begin{tabular}{ccccccccccc}
\hline Species & $\mathrm{SiO}_{2}$ & $\mathrm{Al}_{2} \mathrm{O}_{3}$ & $\mathrm{Fe}_{2} \mathrm{O}_{3}$ & $\mathrm{Na}_{2} \mathrm{O}$ & $\mathrm{K}_{2} \mathrm{O}$ & $\mathrm{CaO}$ & $\mathrm{MgO}$ & $\mathrm{MnO}$ & $\mathrm{TiO}_{2}$ & Igloss \\
\hline Contents $(\%)$ & $55.6-60.5$ & $9.0-10.1$ & $5.7-6.7$ & $0.03-0.11$ & $0.96-1.30$ & $0.42-1.95$ & $10.7-11.35$ & 061 & $0.32-0.6$ & $10.53-11.80$ \\
\hline
\end{tabular}




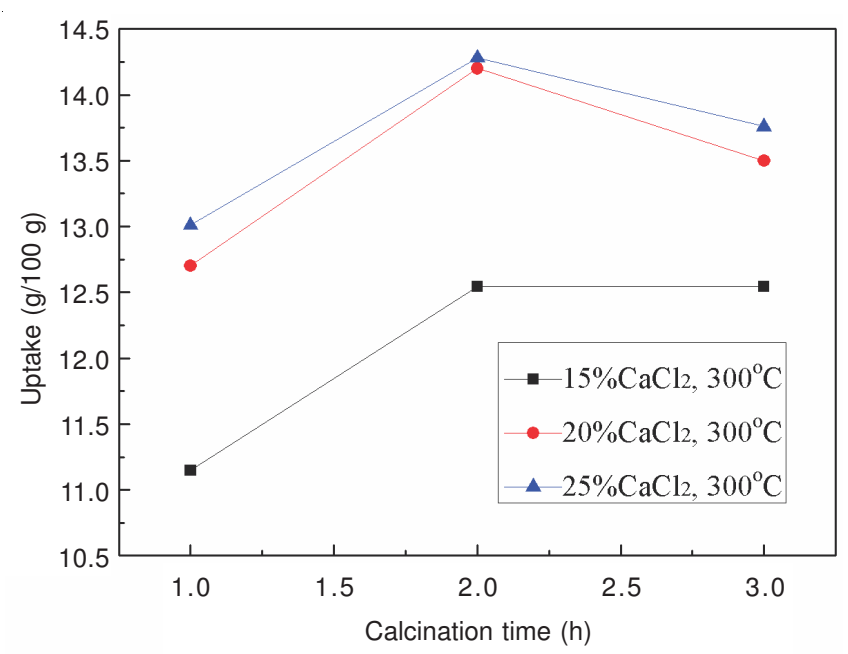

Fig. 1. Water vapour uptake of $\mathrm{CaCl}_{2}$ /attapulgite with different calcination duration

Besides, during the calcination, the water vapour uptake firstly increases and then decreases and the calcination duration of $2 \mathrm{~h}$ leads to the maximum water vapour uptake. The reason for this is that too long calcination duration causes the sinter of $\mathrm{CaCl}_{2}$ in the composite adsorbents, which leads to the decreasing of the water vapour uptake, while too short calcination duration can not form abundant microporous.

Influence of calcination temperature: Fig. 2 displays the water vapour uptake variations of three different $\mathrm{CaCl}_{2} /$ attapulgites with different calcination temperatures at adsorption time of $2 \mathrm{~h}$ and relative humidity of $20 \%$. The figure shows that with the increase of the calcination temperature, the water vapour uptake firstly increases and then decreases and the optimal calcination temperature is $300{ }^{\circ} \mathrm{C}$. For the composite adsorbents with $\mathrm{CaCl}_{2}$ contents of 15,20 and $25 \%$ by weight, the water vapour uptakes of $\mathrm{CaCl}_{2} /$ attapulgite calcined at $300{ }^{\circ} \mathrm{C}$ increase by $0.20,1.21$ and $1.04 \mathrm{~g}$, respectively, compared with that of $250^{\circ} \mathrm{C}$ and $1.05,1.42$ and $1.16 \mathrm{~g}$, respectively, compared with that of $350{ }^{\circ} \mathrm{C}$. This phenomena can be attributed to that the calcination temperature of $250^{\circ} \mathrm{C}$ is too low to completely remove the inner crystal water; there still exits a part of water in the microporous of attapulgite, which results in a smaller water vapour adsorption quantity and the high calcination temperature of $350^{\circ} \mathrm{C}$ can basically completely remove the inner crystal water. However, it will destroy the microporous or channels causing the reduction of specific surface area and thus brings about the reduction of the water vapour adsorption quantity.

Adsorption rate: The performance of adsorbents not only depends on the adsorption capacity but also the adsorption rate. The adsorption rates of the samples with different preparation conditions are shown in Figs. 3 and 4. It can be seen from Fig. 3 that the adsorption rate of the sample with the $\mathrm{CaCl}_{2}$ content of $25 \%$ is highest with adsorption time being $120 \mathrm{~min}$. But in adsorption refrigeration system, the adsorption time is 5-30 min in general. With the adsorption time less than $0.5 \mathrm{~h}$, the adsorption rates of the samples calcined at 300 and $350{ }^{\circ} \mathrm{C}$ are similar and they are all larger than the sample calcined at $250^{\circ} \mathrm{C}$.

Fig. 4 shows that the adsorption rate of the samples with calcination duration of $2 \mathrm{~h}$ is the fastest compared to the others.

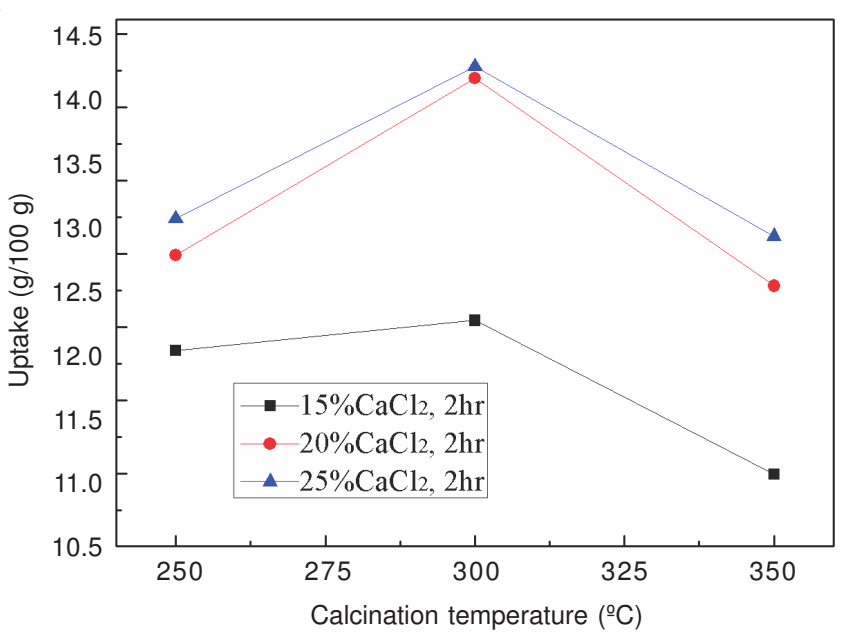

Fig. 2. Water vapour uptake on $\mathrm{CaCl}_{2}$ /attapulgite with different calcination temperature

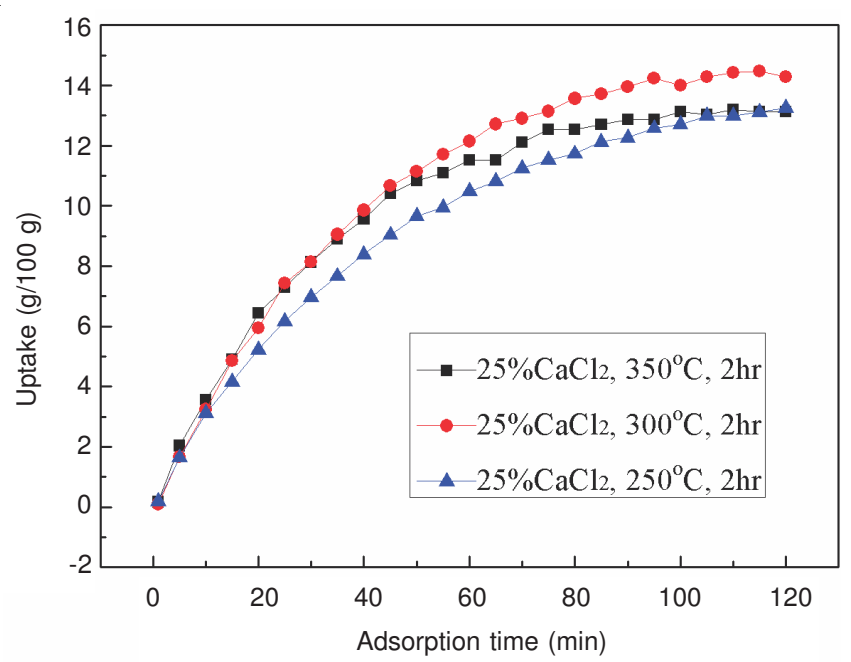

Fig. 3. Adsorption rate of composite adsorbents with calcination temperature

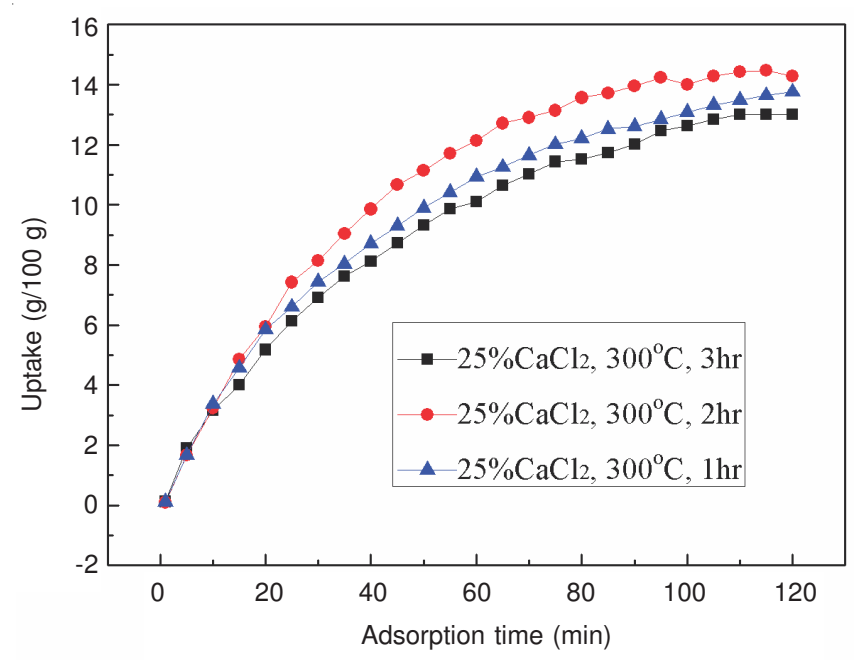

Fig. 4. Effect of calcination duration on adsorption rate of composite adsorbents

However, when the adsorption time is less than $0.5 \mathrm{~h}$, the adsorption rates of the three samples are almost equal. 
Taking the water vapour uptake and adsorption rate into account, the $\mathrm{CaCl}_{2}$ /attapulgite composite adsorbent with the calcination temperature of $300{ }^{\circ} \mathrm{C}$, the calcination time of $2 \mathrm{~h}$ and the $\mathrm{CaCl}_{2}$ content of $25 \%$ is more preferable to refrigeration or air condition applications and it will be chosen for further investigations.

\section{Conclusion}

The high performance adsorbent is the key of the adsorption refrigeration techonology. In this paper, a series of composite adsorbents are prepared by soaking attapulgite into $\mathrm{CaCl}_{2}$ solutions and their adsorption properties are tested in tmeperature and humidity chamber. The influences of $\mathrm{CaCl}_{2}$ content, calcination duration and calcination temperature on the samples are investigated. The results show that the water vapour uptake of the samples increases with the content of $\mathrm{CaCl}_{2}$ increasing. Also, the calcination conditions have an important influence on the adsorption performance of the composite adsorbent of $\mathrm{CaCl}_{2} /$ attapulgite. The optimal calcination duration and temperature are $2 \mathrm{~h}$ and $300^{\circ} \mathrm{C}$, respectively.

Thus, the results of this study demonstrate that the composite absorbent of $\mathrm{CaCl}_{2}$ and attapulgite based on immersion method is more promising and competitive for adsorption refrigeration application. Moreover, the price of the attapulgite is low, there will be a broad market prospects.

\section{ACKNOWLEDGEMENTS}

The work was financially supported by the Innovation Program of Chinese Academy of Sciences (No. y007y51001), the National Natural Science Foundation of China (No. 51106161) and the Guangdong province and Chinese Academy of Science Comprehensive Strategic Cooperation Project (No. 2012B091100263)

\section{REFERENCES}

1. R.Z. Wang and R.G. Oliveira, Progr. Energy Comb. Sci., 32, 424 (2006).

2. R.Z. Wang, Renew. Sustain. Energy Rev., 5, 1 (2001).

3. L.L. Vasiliev, D.A. Mishkinis and A.A. Antukh, J. Int. Adsor. Soc., 7, 149 (2001)

4. K.C.A. Alam, B.B. Saha, Y.T. Kang and A. Akisawa, Int. J. Heat Mass Transfer, 43, 4419 (2000).

5. E.C. Boelman, B.B. Saha and T. Kashiwagi, ASHRAE Trans., 103, 139 (1997).

6. Y.L. Liu, R.Z. Wang and Z.Z. Xia, Int. J. Refriger, 28, 218 (2005).

7. K. Wang, J.Y. Wu, R.Z. Wang and L.W. Wang, Int. J. Refriger., 29, 199 (2006).

8. L.W. Wang, R.Z. Wang, J.Y. Wu and L.W. Wang, Int. J. Refriger, 27, 401 (2004).

9. T. Dellero, D. Sarmeo and P. Touzain, Appl. Thermal Eng., 19, 991 (1999).

10. Y.I. Aristov, Rev. Appl. Thermal Eng., 50, 1610 (2013).

11. K. Daou, R.Z. Wang, Z.Z. Xia and G.Z. Yang, Int. J. Refriger, 30, 68 (2007).

12. L.W. Wang, R.Z. Wang, J.Y. Wu, K. Wang and S.G. Wang, Energy Conv. Manage., 45, 2043 (2004).

13. Y.I. Aristov, G. Restuccia, G. Cacciola and V.N. Parmon, Appl. Therm. Eng., 22, 191 (2002).

14. J.H. Han, K.W. Cho, K.H. Lee and H. Kim, Characterization of GraphiteSalt Blocks in Chemical Heat Pumps: In Proccedings of Absorption Heat Pump Conference, pp. 67-73 (1996).

15. T. Dellero and Ph. Touzain, Appl. Therm. Eng., 19, 1001 (1999).

16. M. Tokarev, L. Gordeeva, V. Romannikov, I. Glaznev and Y. Yuria, Int. J. Therm. Sci., 41, 470 (2002).

17. A.A. Kahira, K.C.A. Alam, Y. Hamamoto, A. Akisawa and T. Kashiwagi, Int. J. Refriger, 27, 225 (2004). 